\title{
Challenges and Tools Available For Various Testing Techniques in Android Mobile Application Testing
}

\author{
Deepika Dhamija \\ Assistant Professor, Amity College of Commerce, \\ Amity University Haryana \\ Ankit Dhamija \\ Assistant Professor, Amity Business School, \\ Amity University Haryana
}

\begin{abstract}
Mobile applications or apps- wow - A need of every Smartphone user. Install, Touch and explore the world with mobile apps. Every user wants to install an app on smart phone but unaware how many types of apps are available. So in this paper we will present types of mobile apps and the challenges faced in different testing.
\end{abstract}

Keywords--Android, testing, mobile, application, software

\section{INTRODUCTION}

What makes a mobile phone a Smartphone? Of course it is the powerful hardware that constitutes a Smartphone; but hardware is not the only factor that defines a Smartphone. A Smartphone is the one that has a vast range of applications (built-in) and supports plenty more from the external apps markets. These apps allow the user to do almost everything that previously required a Desktop PC or a laptop.

People can now, with the use of a Smartphone, stay connected all the time, communicate and collaborate over work in real-time without any lag, conduct meetings, prepare reports and share them with anyone anywhere in the world, and also stay connected with friends, family and communities on various social networks. And you get to do all this without being confined in front of your PC; it doesn't really matter where you are.

So, what exactly are these mobile applications?

Mobile Applications are compact software programs that perform a predefined function and are designed to work on handheld devices such as Smartphone, tablets and feature phones. But all mobile applications are not the same.

There are plenty of considerations when it comes to designing and developing mobile applications. Mobile applications can be broadly classified into three different types based on the mobile development technology employed

to

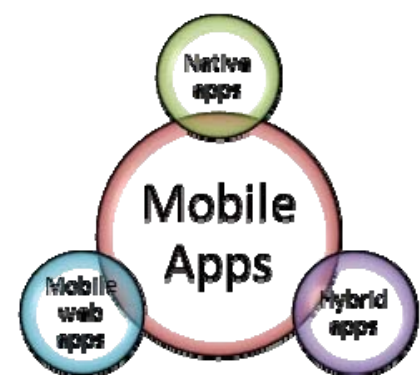

Fig.1 Different types of Mobile Apps create

them.

\section{Native Apps}

Native apps are those apps which are live on the device and are accessed through icons on the device and are installed through an application store(such as Google play store).Developers create them for specifically one platform and can 
take full advantage of all the device features like camera, GPS, list of contacts and so on. Native apps can also work offline. For E.g. Calculator, Facebook etc.

Mobile Web apps

Mobile web are those apps which are actually not real applications and can't be installed from Play store because they are actually websites which are specifically developed, look and feel like native apps. They are run by a browser and typically written in HTML5. For e.g. .Email and chatting application, Online games etc.

Hybrid Apps

Hybrid apps are combination of Native apps and web apps. Like native apps they live in play store and also can take advantage of many device features available.

Like web apps, they rely on HTML5

Hybrid apps are also popular because they allow cross-platform development: that is, the same HTML code components can be reused on different mobile operating systems, reducing significantly the development costs.

For e.g. Banana republic app, Ecommerce apps etc.

\section{MOBILE APPLICATION TESTING}

Mobile applications quality is becoming a very important issue now a day. Users download the apps from app store and can also post reviews. User can use these reviews and can take the decision whether to download the app or not? So there are so many challenges in mobile application testing and different testing techniques are there.

Types of mobile apps testing

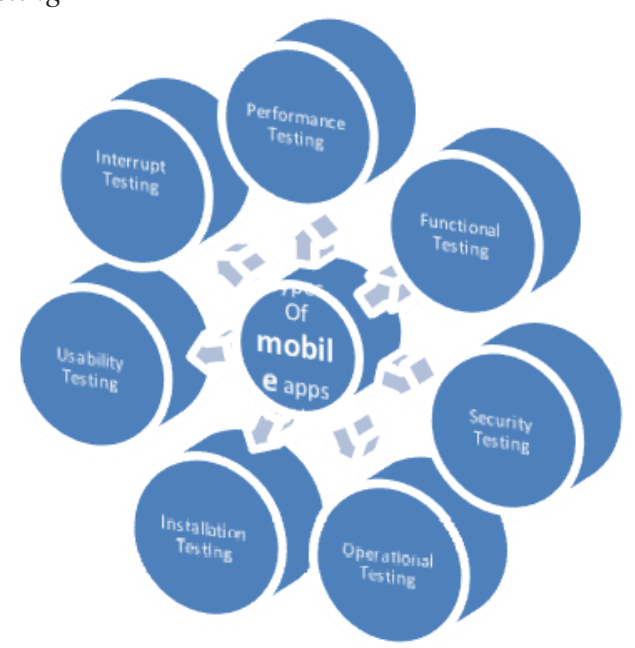

Fig.2 Different Mobile Apps Testing Techniques

\section{PERFORMANCE TESTING}

This testing process is basically used to check the performance and behavior of the application under certain conditions from server and client side both. So tester checks the performance testing on both sides.

\section{Challenges under Performance Testing}

Battery Life: As some of the apps drain battery faster. Applications should not overload CPU with high no. of apps because it decreases the battery life. So the apps which will not be in use should be closed to save the battery.

Launch Time: Launch time refers to the time delay when application starts. According to the consumer expectations survey the median of expected mobile application launch time is two seconds and $80 \%$ of respondents expect that the launch time will be three seconds or less.

Responsiveness: Responsiveness means that the application GUI is able to react quickly without delays or freezes. Mobile users are always in hurry and nobody wants to wait for slow application

Transferring heavy files: When we are transferring heavy files from one network to another with the help of apps, it also decreases the performance of apps, it may slow down the apps functionality. 
This testing is carried out to verify if the application is achieving its goals and getting a favorable response from users.

Challenges in Usability Testing

Connectivity: The slow and unreliable wifi or data connection (wireless network) with low bandwidth is a common obstruction for mobile applications. This problem largely affects data downloading time and quality of streaming media i.e. video and audio streams .Strength of signals and data transfer speed in a wireless network may vary at different time and locations, compounded by user mobility

Small Screen Size: Physical constraints of mobile devices, especially small screen size, can significantly affect the usability of mobile applications. Direct presentation of most WWW pages on small mobile devices can be aesthetically unpleasant, un-navigable, and in the worst case, completely illegible. So Small screen size sometimes unable to open the apps in well-mannered way.

Different Display Resolutions: The display capability of mobile devices supports much less display resolution (normally640*480 pixels or below) in comparison with desktops. Low resolution can degrade the quality of multimedia information displayed on the screen of a mobile Device. As a result, low resolution affects the apps quality and size of the apps visible to user on the screen of mobile.

Limited Processing Capability and Power: Computational power and memory capacity of mobile devices lag far behind desktop computers. Some applications that require a large amount of memory for graphic support or fast processing speed, such as an application of 3D games may not be practical for mobile devices. Because of limited processing capability of mobile devices, developers may have to disable some functions like multimedia games, other apps.

Data Entry Methods: Providing input to small devices is difficult and requires a certain level of proficiency. Small buttons and labels limit users' effectiveness and efficiency in entering data, which may reduce the input speed and increase errors. Results of a usability study can be affected by the use of different data entry methods (e.g., soft versus physical keyboards .Different user status (e.g., sitting versus walking; holding a device in hand or putting it on a table) while using a mobile device can further exacerbate the data entry problem.

\section{INTERRUPT TESTING}

It is a process of testing mobile apps in which the functions of mobile gets interrupted when we are using mobile apps.

\section{Challenges in Interrupt Testing}

Incoming and outgoing SMS/MMS/Calls: When we are using mobile apps, A call arrive between using that apps may interrupt the functioning of apps.

Network Problem: The apps had trouble with network or responded slowly .New version can never connect to server.

Incoming notifications: The messages, mails, other notifications sometimes may interrupt in the functioning of apps results in forcing in closing of the apps.

Low battery: users have to keep an eye on the drainage of battery because it results in closing of the apps and apps gets automatically move to suspended state and have to be restart again.

Low memory Warning: Some apps require more ram and storage space for running the apps and to open an app ensure that your phone has sufficient memory and low memory warning also interrupts in running of the apps.

\section{FUNCTIONAL TESTING}

Functional testing performs on the functional behavior of the application to ensures that the application is working as per the requirements. Mostly, testing performs on the user interface and call flows of the application. As like other UI applications mobile applications also require lots of human consideration. If, functional testing performs on mobile devices manually, not automatically, it is going to be extremely complex, exhaustive and time-consuming task due to various mobile-specific challenges 


\section{Challenges in Functional Testing}

Apps Interface Design: The user complains about the design, controls or visuals. So the apps functionality should be easily understandable for a layman.

Apps Design: Some problems or notifications are app specific i.e. we will not get the notifications unless you actually open the app.

Different modes of network: Some apps has meeting and flying modes and users are unaware of these apps modes.

\section{SECURITY TESTING}

The purpose of security testing to test the application's data and network security to check the application's data and network security is responding as per the given requirement/guideline

\section{Challenges in Security Testing}

Data storage: $75 \%$ of applications do not use proper encryption techniques when storing data or leave them unencrypted. So data should be stored in proper locations and no sensitive information was stored unencrypted.

\section{OPERATIONAL TESTING}

Any mobile OS and desktop OS provides in-built back-up and recovery operational functions that save or recover all files or doc of mobile devices or applications that had been lost due to some reason. Operational testing is used to test that the particular back-up and recovery process is working properly and responding as per the requirement.

\section{Challenges in Operational Testing}

OS Version: Mobile application developers get new versions of OS in advance to have a time to prepare their applications. OS updates are common cause of application crashes. Test application after OS updates can be convenient on mobile test cloud, but many of them do not support test flow when application is installed on device with specific OS version and OS is consequently updated on higher version.

\section{INSTALLATION TESTING}

The mobile applications are either pre-installed on the device or can be downloaded from any store. The installation testing is not necessary if the application is pre-installed. But in case user is downloading and installing an application on the device, this testing must be done to ensure a smooth installation without any difficulties. This testing focuses on each step of the installation process that a user has to follow. Usually the methods followed for downloading an application are 'Over the Air', 'through cable', SD Card, and Bluetooth. This testing covers installation, upgrade, and uninstallation of the application.

\section{Challenges in Installation Testing}

Up gradation: Some apps require up gradation or if a new version or upgrade of an app available, it requires a more space, so due to less storage apps doesn’t functioning well.

Uninstallation: Some apps are using the useful information of some other apps and uninstallations of that app also affect other apps and sometimes apps may get crashed or corrupt. 


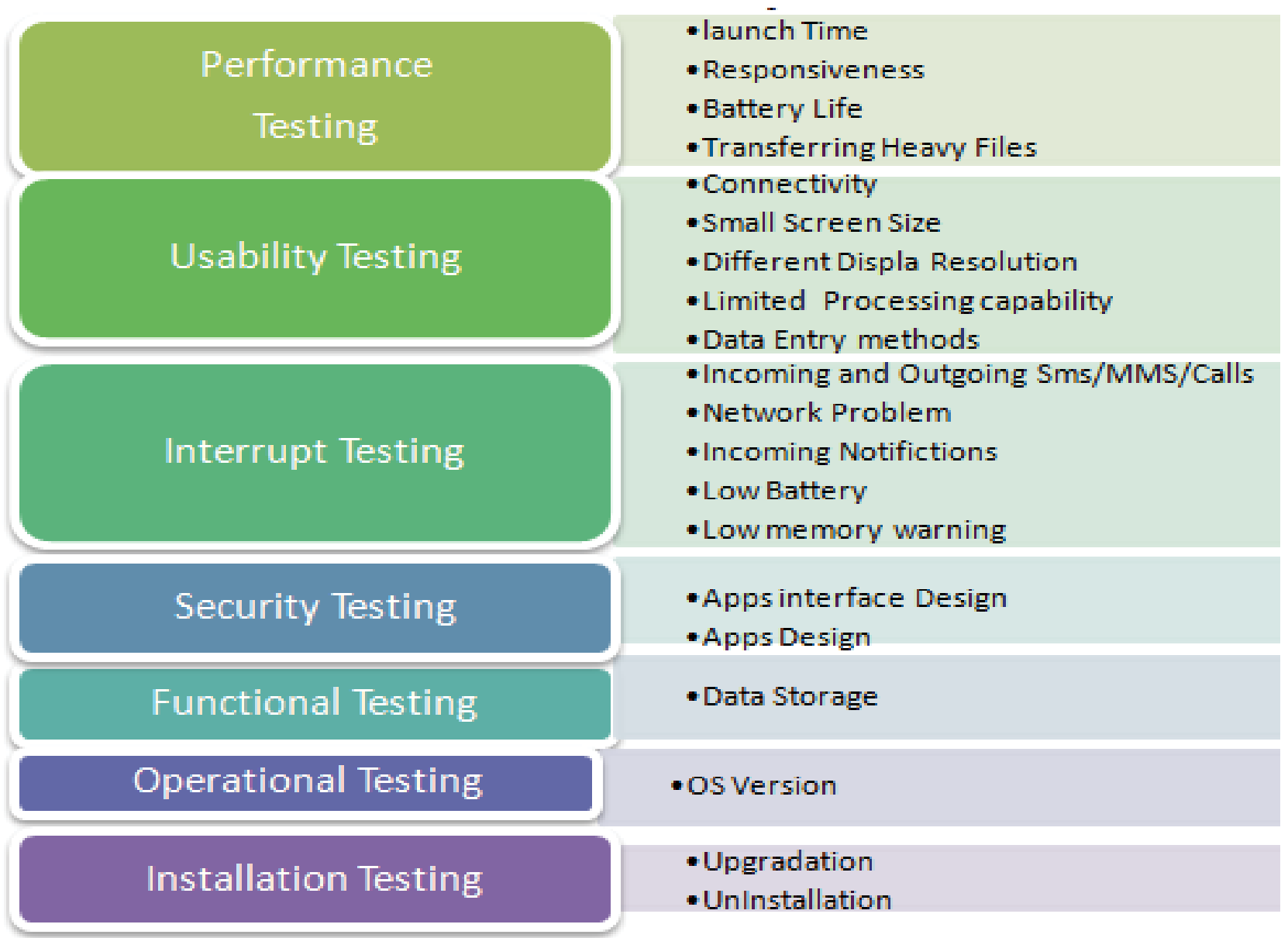

Fig.3 Challenges in Mobile Apps Testing Summarized

\section{TESTING TOOLS}

Testing the mobile apps now days is a big challenge. So to test the mobile apps various emulators and simulators are available. So for each testing techniques various tools are available. In this section we will figure out the tools and software available for performing all the above mentioned testing types.

\begin{tabular}{|l|l|l|l|l|l|l|l|}
\hline \multirow{2}{*}{ Tools } & \multicolumn{2}{|l|}{ Features } & License & $\begin{array}{l}\text { Testing } \\
\text { Types }\end{array}$ \\
\cline { 2 - 5 } & $\begin{array}{l}\text { Supporting } \\
\text { Device }\end{array}$ & $\begin{array}{l}\text { Optical } \\
\text { Charact } \\
\text { er } \\
\text { Recognit } \\
\text { ion }\end{array}$ & Reports & $\begin{array}{l}\text { Scripting } \\
\text { Language }\end{array}$ & $\begin{array}{l}\text { External } \\
\text { Resources }\end{array}$ & & \\
\hline $\begin{array}{l}\text { TPlan } \\
\text { Robot }\end{array}$ & $\begin{array}{l}\text { iPhone,Android } \\
\text { Etc }\end{array}$ & Yes & $\begin{array}{l}\text { 7. Reports } \\
\text { with test } \\
\text { results and } \\
\text { screenshots in } \\
\text { HTML format }\end{array}$ & Java & $\begin{array}{l}\text { Reading from and } \\
\text { writing to plain } \\
\text { text files, CSVs } \\
\text { and MS Excel } \\
\text { documents }\end{array}$ & OPen & $\begin{array}{l}\text { Functional } \\
\text { Testing } \\
\text { Interrupt } \\
\text { testing }\end{array}$ \\
\hline $\begin{array}{l}\text { Device } \\
\text { AnyWhere }\end{array}$ & $\begin{array}{l}\text { iOS, Android, } \\
\text { BlackBerry, } \\
\text { Win 7, WebOS. }\end{array}$ & Yes & $\begin{array}{l}\text { Test reports } \\
\text { are } \\
\text { automatically }\end{array}$ & Java & $\begin{array}{l}\text { Reading from and } \\
\text { writing to plain } \\
\text { text files, CSVs }\end{array}$ & Cost & $\begin{array}{l}\text { Cunctionality, } \\
\text { usability, } \\
\text { performance }\end{array}$ \\
\hline
\end{tabular}




\begin{tabular}{|c|c|c|c|c|c|c|c|}
\hline & & & $\begin{array}{l}\text { stored in the } \\
\text { DeviceAnywh } \\
\text { ere Proof } \\
\text { Center and can } \\
\text { also be } \\
\text { generated into } \\
\text { exportable } \\
\text { files. }\end{array}$ & & $\begin{array}{l}\text { and MS Excel } \\
\text { documents not } \\
\text { support in } \\
\text { DeviceAnyWhere }\end{array}$ & & \\
\hline Perfeco & $\begin{array}{l}\text { iOS, Android, } \\
\text { BlackBerry, } \\
\text { Win 7, WebOS. }\end{array}$ & Yes & $\begin{array}{l}\text { screen } \\
\text { captures in } \\
\text { digital format, } \\
\text { continuous } \\
\text { video } \\
\text { recording of } \\
\text { the entire } \\
\text { script and } \\
\text { graphs } \\
\text { showing } \\
\text { statistics about } \\
\text { the execution }\end{array}$ & $\begin{array}{l}\text { A Single } \\
\text { script }\end{array}$ & $\begin{array}{l}\text { Supports text files } \\
\text { and CSV files }\end{array}$ & Cost & $\begin{array}{l}\text { GUI ,usability } \\
\text { Testing }\end{array}$ \\
\hline $\begin{array}{l}\text { Egg } \\
\text { Plant }\end{array}$ & $\begin{array}{l}\text { iOS, Android, } \\
\text { BlackBerry, } \\
\text { Win 7, WebOS }\end{array}$ & Yes & $\begin{array}{l}\text { Not } \\
\text { Applicable }\end{array}$ & $\begin{array}{l}\text { Egg Plant } \\
\text { Own } \\
\text { scripting } \\
\text { Language }\end{array}$ & $\begin{array}{l}\text { Reading from and } \\
\text { writing to CSVs } \\
\text { and MS Excel } \\
\text { documents }\end{array}$ & Cost & $\begin{array}{l}\text { Functional } \\
\text { Testing }\end{array}$ \\
\hline $\begin{array}{l}\text { See } \\
\text { Test }\end{array}$ & $\begin{array}{l}\text { Android } \\
\text { iOS (iPhone, } \\
\text { iPad) - all } \\
\text { versions inc. } \\
\text { iOS5 } \\
\text { Blackberry, } \\
\text { WindowsMobil } \\
\text { e, } \\
\text { Symbian }\end{array}$ & Yes & $\begin{array}{l}\text { Reports with } \\
\text { test results and } \\
\text { screenshots in } \\
\text { HTML format }\end{array}$ & $\begin{array}{l}\text { python,perl } \\
\text {,Java }\end{array}$ & Not Applicable & Cost & $\begin{array}{l}\text { Usability } \\
\text { Testing }\end{array}$ \\
\hline
\end{tabular}

Table 1: COMPARATIVE ANALYSIS OF DIFFERENT TESTING TOOLS

\section{CONCLUSION}

This paper has tried to provide an overview on what testing mobile applications is all about where we had tried to provide different types of testing techniques for android applications and what challenges the tester face while testing such apps. We had also provided a comparative analysis of several mobile app testing tools which are mostly used and which cover most of the issues that arise in mobile app testing

\section{REFERENCES}

[1] Varshey, U., \& Vetter, R. (2002). Mobile Commerce: Framework, Applications and Networking Support. Mobile Networks and Applications, 7, 185-198

[2] B. Jiang, X. Long, X. Gao, Z. Liu, and C. W.K., "FLOMA: Statistical fault localization for mobile embedded system," in 3rd International Conference on Advanced Computer Control (ICACC), January 2011, pp. 396-400.

[3] http://userpages.umbc.edu/ zhangd/Papers/IJHCI1.pdf

[4] http://www.socialhunt.net/blog/types-of-mobile-app/

[5] https://www.nngroup.com/articles/mobile-native-apps/

[6] http://blog.deepbluesky.com/blog/-/what-is-a-mobile-app 161/

[7] http://ieeexplore.ieee.org/stamp/stamp.jsp?tp=\&arnumber $=6228987 \&$ isnumber $=6228973$ 